\title{
Cx32 inhibits TNF $\alpha$-induced extrinsic apoptosis with and without EGFR suppression
}

\author{
YONGCHANG LAI $^{1,2^{*}}$, LIANG TAO $^{1 *}$, YIFAN ZHAO $^{4}$, XIAOMIN ZHANG $^{1}$, \\ XINGJUAN SUN ${ }^{5}$, QIN WANG ${ }^{1}$ and CHENGFANG XU ${ }^{3}$

\footnotetext{
${ }^{1}$ Department of Pharmacology, Zhongshan School of Medicine, Sun Yat-sen University, Guangzhou, Guangdong 510080; ${ }^{2}$ Department of Urology, Minimally Invasive Surgery Center, The First Affiliated Hospital of Guangzhou Medical University, Guangzhou Urology Research Institute, Guangdong Key Laboratory of Urology, Guangzhou, Guangdong 510230;

${ }^{3}$ Department of Obstetrics and Gynecology, The Third Affiliated Hospital, Sun Yat-sen University, Guangzhou, Guangdong 510630; ${ }^{4}$ Department of Anesthesiology, Sun Yat-sen Memorial Hospital, Sun Yat-sen University;

${ }^{5}$ Traditional Chinese Medicine Hospital of Guangdong, Guangzhou, Guangdong 510120, P.R. China
}

Received March 22, 2017; Accepted July 21, 2017

DOI: $10.3892 / o r .2017 .5950$

\begin{abstract}
Tumor necrosis factor $\alpha(\mathrm{TNF} \alpha)$ and TNF-related apoptosis-inducing ligand (TRAIL) can trigger the extrinsic apoptosis pathway. Our previous study indicated that connexin32 (Cx32) inhibited streptonigrin-induced intrinsic apoptosis via the epidermal growth factor receptor (EGFR) pathway. However, whether Cx32 can exert effects on the extrinsic apoptosis pathway through EGFR signaling remains unclear. In the present study, we investigated the role of $\mathrm{Cx} 32$ in extrinsic apoptosis induced by treatment with $\mathrm{TNF} \alpha+$ cycloheximide $(\mathrm{CHX})$ or afatinib in human cervical cancer (CaCx) cells. In stable inducible Cx32-transfected HeLa cells (HeLa-Cx32), Cx32 expression was induced by treatment with doxycycline (Dox). Furthermore, C-33A cells, which natively express high levels of $\mathrm{Cx} 32$, were used as a cell model for knockdown of $\mathrm{Cx} 32$ with siRNA. To determine the non-junctional function of $\mathrm{Cx} 32$ in apoptosis, $18 \alpha$-glycyrrhetinic acid (18 $\alpha-\mathrm{GA})$, a gap junction intracellular communication (GJIC) inhibitor, was used. Our results showed that $\mathrm{Cx} 32$ could inhibit apoptosis induced by $\mathrm{TNF} \alpha+$ afatinib with or without the GJIC inhibitor. In clinical cervical tissue samples, we found that the expression of survivin was markedly higher in $\mathrm{CaCx}$ than in normal cervix tissue, which was in accordance with the expression of Cx32 in our previous study. In HeLa-Cx32 cells,
\end{abstract}

Correspondence to: Dr Chengfang Xu, Department of Obstetrics and Gynecology The Third Affiliated Hospital, Sun Yat-sen University, 600 Tianhe Road, Guangzhou, Guangdong 510630, P.R. China

E-mail: lindaxu2011@qq.com

*Contributed equally

Key words: gap junction, Connexin32, cervical cancer, TNF $\alpha$, epidermal growth factor receptor, apoptosis we also found that Cx32 upregulated the expression of Cox-2. In addition, Cx32 upregulated EGFR expression in low-density culture (lacking GJ formation). Cx32 could also promote the expression of EGFR, phospho-STAT3 and phospho-ERK in HeLa-Cx32 cells following TNF $\alpha$ treatment. After knocking down Cx32 in C-33A cells, the expression levels of survivin and TNF $\alpha$ were downregulated. The present study verifies that $\mathrm{Cx} 32$ exerts an inhibitory effect on extrinsic apoptosis in $\mathrm{CaCx}$ cells, and suggests that $\mathrm{Cx} 32$ may regulate the progression and micro-environment of $\mathrm{CaCx}$ cells.

\section{Introduction}

Gap junctions (GJs), principally composed of connexins (Cxs), are important for communication between tumor cells and stromal cells. Increased GJ coupling has been reported to hinder metastatic potential in a number of animal tumor models, including breast cancer and melanoma (1). Although many studies sustain the viewpoint that Cxs are tumor suppressors, recent evidence suggests that, in some tumor types, they may promote certain stages of tumor progression through junctional and non-junctional pathways (2). Cx26, but not $\mathrm{Cx} 40$ or Cx43, was shown to suppress tumorigenic features in cervical cancer $(\mathrm{CaCx}) \mathrm{HeLa}$ cells, even though all three $\mathrm{Cxs}$ increased GJ intracellular communication (GJIC) (3). Downregulation in Cx32 results in the proliferation and metastasis of hepatocellular carcinoma (HCC), and the restoration of Cx32 expression may be a prospective strategy for the treatment of HCC (4). However, accumulation of cytoplasmic Cx32 can increase the self-renewal of cancer stem cells (CSCs) to expand the CSC population in $\mathrm{HCC}(5)$.

Tumor necrosis factor $\alpha(\mathrm{TNF} \alpha)$ activates caspase- 8 in the extrinsic pathway of apoptosis. Aberrant secretion of TNF $\alpha$ facilitates a number of human diseases and has been implicated in tumor development and inflammation (6). In particular, TNF $\alpha$ polymorphisms have been associated with cervical cancer (7). Persistent high-risk human papillomavirus (HPV) infection gives rise to inflammation-associated $\mathrm{CaCx}$ 
progression. HPV-negative head and neck cancers express epidermal growth factor receptor (EGFR) to a high level, and a monoclonal antibody for EGFR (cetuximab) is currently the only targeted therapy that has improved survival in patients with this disease (8). To prevent the retention of HPV within cells, TNF $\alpha$-induced apoptosis is a key defense strategy (9); however, the function of Cx32 proteins in this mechanism of extrinsically triggered cell death remains unknown.

Our previous study demonstrated that $\mathrm{Cx} 32$ regulated EGFR expression and exerted a pro-tumor effect in $\mathrm{CaCx}$ (10). Cx32 can suppress endogenous apoptosis induced by streptonigrin in $\mathrm{CaCx}$. However, the role of $\mathrm{Cx} 32$ in $\mathrm{TNF} \alpha$-induced extrinsic apoptosis is unclear. A high $\mathrm{CaCx}$ systemic inflammation score has been correlated with more advanced FIGO stages and poor tumor differentiation (11). In the present study, we investigated whether $\mathrm{Cx} 32$ was a key regulator of tumor growth associated with $\mathrm{TNF} \alpha$-related inflammation.

\section{Materials and methods}

Materials. Dimethyl sulfoxide (DMSO), $18 \alpha$-glycyrrhetinic acid (18 $\alpha$-GA), 2-aminoethoxydiphenyl-borate (2-APB), anti$\beta$-tubulin and anti- $\beta$-actin mouse IgG primary antibodies, and secondary antibodies were purchased from Sigma-Aldrich (St. Louis, MO, USA). Anti-Cx32 antibody was purchased from Santa Cruz Biotechnology, Inc. (Santa Cruz, CA, USA). Antibodies against Cox2, EGFR, p-ERK1/2 (Thr202/Tyr204), STAT3, p-STAT3 (Tyr705), TNF $\alpha$ and survivin were obtained from Cell Signaling Technology, Inc. (Danvers, MA, USA). TNF $\alpha$ was obtained from PeproTech, (Rocky Hill, NJ, USA). Hygromycin B, G418 and doxycycline (Dox) were obtained from Calbiochem (San Diego, CA, USA). An Annexin V-FITC apoptosis detection kit was purchased from BioTool, LLC (Houston, TX, USA). Cycloheximide (CHX) was purchased from Beijing Dingguo Changsheng Biotechnology, Co., Ltd. (Beijing, China). Lipofectamine ${ }^{\mathrm{TM}} 2000$ was purchased from Gibco (Carlsbad, CA, USA). Calcein-AM (acetoxymethyl ester) was obtained from Invitrogen (Carlsbad, CA, USA). All other reagents were purchased from Sigma-Aldrich unless stated otherwise.

Clinical tissue specimens. The clinical cervical carcinoma and para-carcinoma tissue samples were obtained from the Affiliated Tumor Hospital of Xinjiang Medical University (Urumqi, China). Cervical tissue samples $(n=15)$ were resected during surgery. The use of these clinical samples was approved by the ethics committee of Xinjiang Medical University Affiliated Tumour Hospital.

Cell lines and cell culture. The C-33A cell line was acquired from the American Type Culture Collection (ATCC; Manassas, VA, USA). C-33A cells were cultured in minimum essential medium supplemented with $10 \%$ fetal bovine serum (FBS). Cx32 under the control of a bidirectional tetracycline-inducible promoter was stably transfected into HeLa cells (HeLa-Cx32) for subsequent induction of $\mathrm{Cx} 32$ expression via incubation with Dox $(1 \mu \mathrm{g} / \mathrm{ml})$ for $\sim 48 \mathrm{~h}$ (12). Prior to treatment with Dox, $100 \mu \mathrm{g} / \mathrm{ml} \mathrm{G} 418$ sulfate and $200 \mu \mathrm{g} / \mathrm{ml}$ hygromycin B were added to the medium [Dulbecco's modified Eagle's medium (DMEM) supplemented with 10\% FBS] to select for stably transfected cells. Besides high-density culturing, we also use a low-density culture method, and the HeLa-Cx32 cells were seeded into $150-\mathrm{mm}$ dishes. At this low-density, there was a lack of cell-cell contacts, which prevented the formation of GJs and enabled investigation into the non-junctional function of Cx32 in apoptosis.

GJfunctional assay. GJIC function was evaluated using a 'parachute' dye coupling assay, as described by Goldberg et al (13) and Koreen et al (12). The experiment was devided into control group, Dox group, Dox $+18 \alpha-$ GA group and Dox+2APB group. In this assay, donor and receiver HeLa-Cx32 cells were grown to confluence in 12-well plates. After the cells were cultured to confluence, donor cells were labeled with $5 \mu \mathrm{M}$ calcein-AM for $30 \mathrm{~min}$ at $37^{\circ} \mathrm{C}$. The donor cells were then rinsed, trypsinized and seeded onto the receiver cells at a 1:150 donor/receiver ratio. The donor cells were incubated at $4 \mathrm{~h}$ at $37^{\circ} \mathrm{C}$ to allow attachment to the monolayer of receiver cells and the formation of GJs. Cells were subsequently observed under a fluorescence microscope (Olympus IX71; Olympus Corp., Tokyo, Japan). Donor cells can be labeled and observed by strong calcein-AM staining. Calcein-AM from donor cells can be intracellularly transferred into receiver cells when GJIC is present. The level of GJIC was measured as the average number of receiver cells containing Calcein-AM per donor cell observed by fluorescence microscopy.

Cx32 siRNA and EGFR interference assay. After growing C-33A cells to $30-50 \%$ confluence, $50 \mathrm{nM}$ of non-specific (NS) siRNA (negative control) or Cx32-siRNA (Guangzhou RiboBio, Co., Ltd., Guangzhou, China) and Lipofectamine ${ }^{\mathrm{TM}}$ 2000 were mixed and added to cells. Lipofectamine ${ }^{\mathrm{TM}} 2000$ was used to transfect cells according to the manufacturer's protocol. After incubation with the siRNAs for $48 \mathrm{~h}$, further experiments were conducted in the cells.

For the subsequent knockdown of EGFR, the following EGFR siRNAs were synthesized: siEGFR_1,5'-GGCTGGTTA TGTCCTCATT-3'; siEGFR_2, 5'-CCTTAGCAGTCTTATCT AA-3'; and siEGFR_3, 5'-GGAACTGG ATATTCTGAAA-3'. Among them, siEGFR_1 was determined to be the most effective by western blot analysis, and was selected for an EGFR targeting assay.

For the subsequent knockdown of $\mathrm{Cx} 32$, the following Cx32 siRNAs were synthesized: siCx32_1, 5'-CCGGCATTC TACTGCCATT-3'; siCx32_2, 5'-GGCTCACCAGCAACAC ATA-3'; and siCx32_3, 5'-GCAACAGCGTTTGCTATGA-3'. Among them, siCx32_3 was chosen for further experiments after confirmation by western blot analysis.

Apoptosis assay. Approximately $1-2 \times 10^{5} \mathrm{HeLa}-\mathrm{Cx} 32$ cells/well were seeded into 6-well plates. After adherence, the cells were incubated with Dox or DMSO for $48 \mathrm{~h}$. TNF $\alpha(100 \mathrm{ng} / \mathrm{ml})$ was then added to the HeLa-Cx32 cells for $24 \mathrm{~h}$, and cells were incubated with $\mathrm{CHX}(0.1$ or $1 \mu \mathrm{g} / \mathrm{ml})$ or afatinib $(1.25 \mu \mathrm{M})$ except EGFR siRNA group. The cells were washed twice with phosphate-buffered saline (PBS) and trypsinized, terminated by medium and harvested. After the cells were centrifuged at 1,000 $\mathrm{rcf}$ for $5 \mathrm{~min}$ at room temperature and resuspended with PBS twice, binding buffer and Annexin V-FITC with propidium iodide (PI) were used to stain cells for 15 min away 
A


Dox

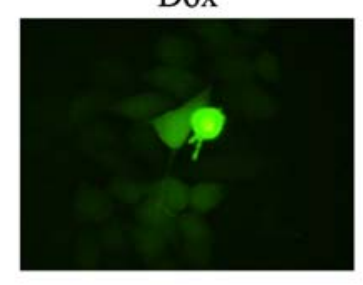

Dox +2 APB

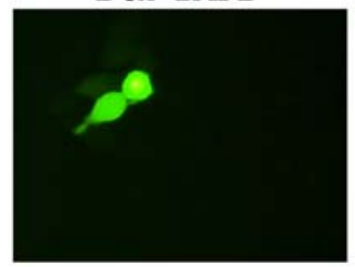

B

Cx32

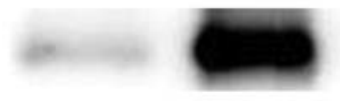

$32 \mathrm{kDa}$

Tubulin

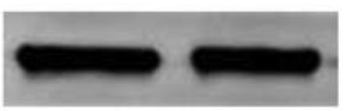

Control

Figure 1. Inducible Cx32 expression model in HeLa cells (HeLa-Cx32) confirmed by western blot analysis. (A) Parachute assay of HeLa-Cx32 cells divided into the following 4 groups: Control, Dox, Dox $+18 \alpha-G A$ and Dox+2APB. GJ function was detected after Cx 32 induction with Dox, although was subsequently inhibited by $18 \alpha-$ GA or 2 APB treatment. (B) Western blot analysis verified that Dox could induce the expression of $\mathrm{Cx} 32$ in $\mathrm{HeLa}-\mathrm{Cx} 32$ cells. $\mathrm{P}<0.05$; $\mathrm{n}=3$; $\mathrm{n}=1$ represents an independent experiment.

from light at room temperature. Subsequently, the cells were immediately analyzed with a flow cytometer. Expo32 software was used to determine the rate of early apoptosis.

Western blotting. Homogenized tissue samples (50-100 mg) or cells were rinsed with PBS and treated with ice-cold lysis-buffer [1 mM $\beta$-glycerophosphate, $2.5 \mathrm{mM}$ sodium pyrophosphate, $20 \mathrm{mM}$ Tris- $\mathrm{HCl}(\mathrm{pH} 7.4), 1 \%$ Triton $\mathrm{X}-100$, $150 \mathrm{mM} \mathrm{NaCl}, 1 \mathrm{mM}$ EGTA, $1 \mathrm{mM}$ EDTA, $1 \mathrm{mM} \mathrm{Na}_{3} \mathrm{VO}_{4}$ and 1:1,000 protease inhibitors) for at least $30 \mathrm{~min}$. After scraping, collection and ultrasonication, the lysate solutions were centrifuged at $12,000 \mathrm{rcf}$ for $30 \mathrm{~min}$ at $4^{\circ} \mathrm{C}$, and the supernatant was retained. A BCA protein assay kit (Thermo Fisher Scientific, Waltham, MA, USA) was used to measure protein concentration. For western blotting, equal amounts $(20 \mu \mathrm{g})$ of protein were prepared and separated by SDS-PAGE and transferred to PVDF membranes. The membranes were blocked with $5 \%(\mathrm{w} / \mathrm{v})$ skimmed dry milk in wash buffer [TBS and $0.05 \%$ Tween-20 (TBST)] for $1 \mathrm{~h}$. The membranes were then incubated with monoclonal antibodies against Cx32 (1:1,000), EGFR (1:1,000), p-ERK (1:1,000), STAT3 (1:1,000), p-STAT3 (1:1,000), Cox-2 (1:1,000), survivin (1:1,000), TNFa (1:1,000), $\beta$-actin $(1: 10,000)$ and $\beta$-tubulin $(1: 10,000)$ overnight at $4{ }^{\circ} \mathrm{C}$. HRP-conjugated secondary antibodies were applied to the membranes for $1-2 \mathrm{~h}$ at room temperature, and the membrane was then washed with TBST. Immunoreactive bands on the membrane were visualized using Western Lightning chemiluminescence reagents (Thermo Fisher Scientific). $\beta$-tubulin and $\beta$-actin were used as control markers. The control bands were set as '100' and the fold changes in each sample's ratio to the control bands were used as the finalized data.

Statistical analysis. All experiments were repeated at least three times. The data were presented as the mean \pm standard error (SE) and analyzed using the SPSS 16.0 software. Statistical significance $(\mathrm{P}<0.05)$ was analyzed by one-way ANOVA ( $>2$ groups) or a Student's t-test (2 groups). Western blot data was analyzed with the ImageJ software. Histograms or scatter diagrams were constructed with the Prism software. $\mathrm{P}<0.05$ indicates a significant difference.

\section{Results}

Inducible Cx32 expression model in HeLa cells (HeLa-Cx32) confirmed by western blot analysis. The GJ function of the HeLa-Cx32 cell model was assessed with a parachute assay, as depicted in Fig. 1A. Results of the control group, Dox group, Dox $+18 \alpha-$ GA group and Dox +2 APB group are displayed in the figure. The results showed that after induction with Dox, GJs were formed, and also indicated that $18 \alpha-\mathrm{GA}$ and $2 \mathrm{APB}$ could effectively suppress GJ function. The drug concentrations of $10 \mu \mathrm{M} 18 \alpha-\mathrm{GA}$ and $50 \mu \mathrm{M} 2 \mathrm{APB}$ were selected according to our former study (10). As shown in Fig. 1B, western blotting indicated that Dox induced high-level expression of Cx32, and thus this cell model was used in subsequent experiments.

Cx32 expression and EGFR-related signal molecules in the different HeLa-Cx32 cell groups. As shown in Fig. 2A, a low-density culture was established to prevent GJ formation and the expression of EGFR was subsequently detected. We found that $\mathrm{Cx} 32$ could modulate EGFR expression without GJ formation. Furthermore, after incubation with TNF $\alpha$ for $24 \mathrm{~h}$, the high expression levels of Cx32 in HeLa-Cx32 cells (induced by Dox) could promote the expression of EGFR, p-STAT3 and p-ERK, without changing the expression of total STAT3 (Fig. 2B). These results indicated that Cx32 could upregulate EGFR not only in the absence of GJ formation, but also after treatment with TNF $\alpha$.

Cx32 inhibits apoptosis induced by TNF $\alpha$ plus CHX or afatinib in HeLa-CX32 cells. According to the reported ability of TNF $\alpha$ to induce apoptosis (14), we used TNF $\alpha(50 \mathrm{ng} / \mathrm{ml})$ $+\mathrm{CHX}(0.1$ or $1 \mu \mathrm{g} / \mathrm{ml})$ to induce apoptosis, as depicted in Fig. 3A. The results showed that apoptosis induced by TNF $\alpha$ and $\mathrm{CHX}$ co-treatment was inhibited by $\mathrm{Cx} 32$ upregulation following treatment with the GJ inhibitor $18 \alpha-$ GA. Afatinib 
A

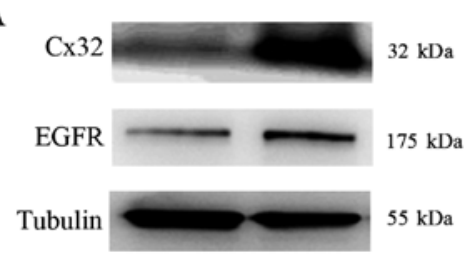

B

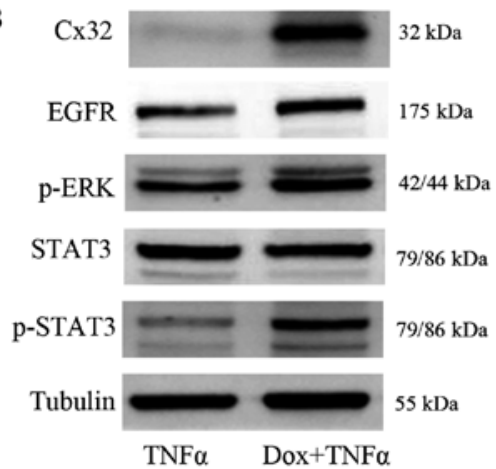

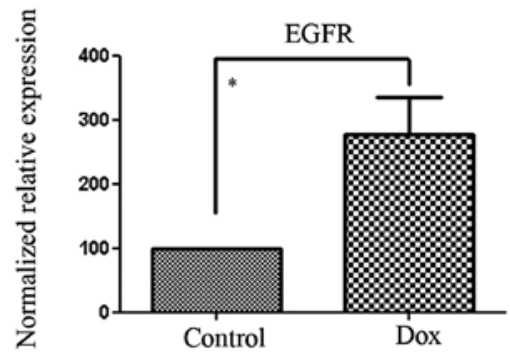

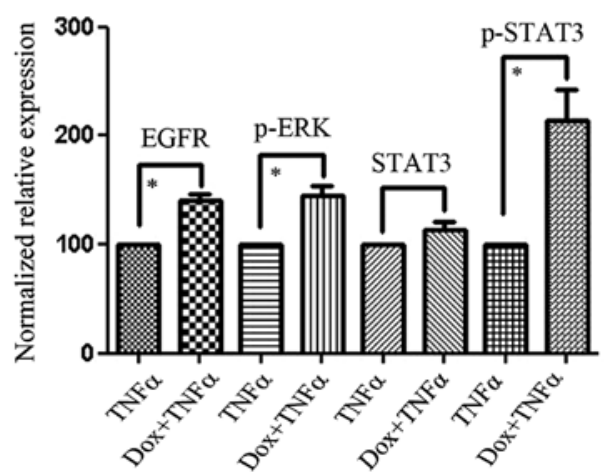

Figure 2. Cx32 expression and EGFR-related signal molecules in the different HeLa-Cx32 cell groups. (A) A low-density culture of HeLa-Cx32 cells was established to block GJ formation, and the expression of EGFR was detected. (B) After incubation with TNFa for $24 \mathrm{~h}$, high-level Cx32 expression (induced by Dox) could promote the expression of EGFR, phospho-STAT3 and phospho-ERK, without changing the expression of STAT3. ${ }^{*} \mathrm{P}<0.05 ; \mathrm{n}=3-5, \mathrm{n}=1$ represents an independent experiment.

A
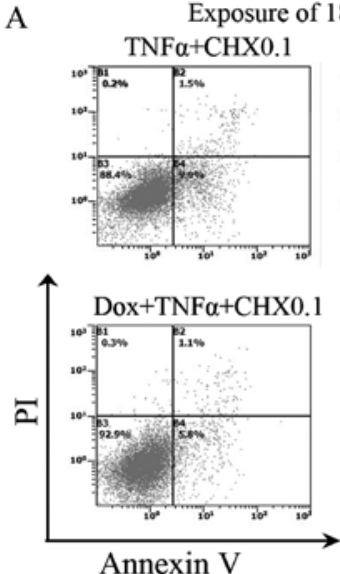

B


Annexin V
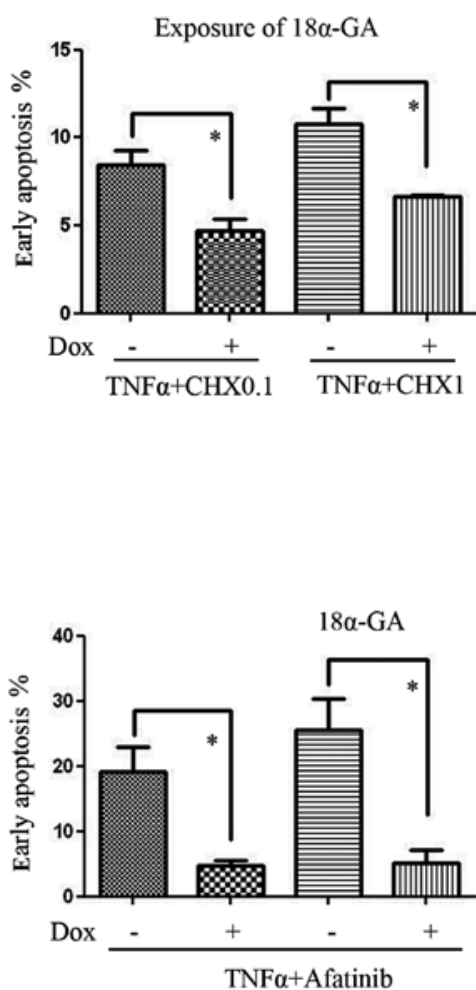

TNF $\alpha+$ Afatinib


Dox + TNF $\alpha+$ Afatinib $+18 \alpha-G A$



Figure 3. Cx32 inhibited apoptosis induces by TNF $\alpha$ plus CHX or afatinib in HeLa-Cx32 cells. (A) Cell apoptosis induced by TNF $\alpha+C H X$ co-treatment was inhibited by $\mathrm{Cx} 32$ expression following treatment with the GJ inhibitor 18 $\alpha$-GA. (B) Afatinib was used in co-treatment with TNF $\alpha$ to inhibit EGFR, and the results showed that, with and without GJ inhibition by $18 \alpha-\mathrm{GA}$, the anti-apoptotic effect of $\mathrm{Cx} 32$ against TNF $\alpha$ was present. ${ }^{*} \mathrm{P}<0.05 ; \mathrm{n}=3-4$; $\mathrm{n}=1$ represents an independent experiment. 
A
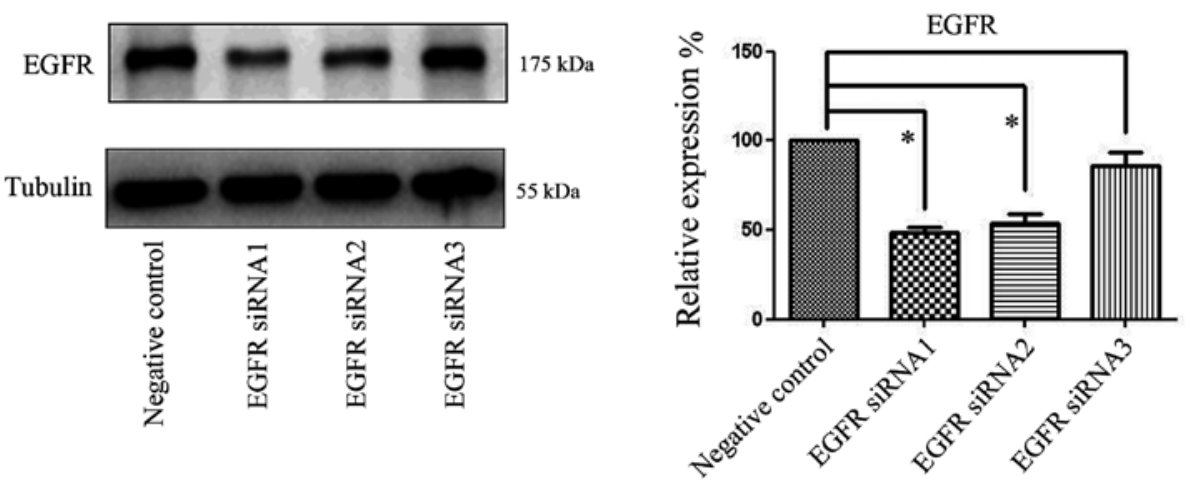

B

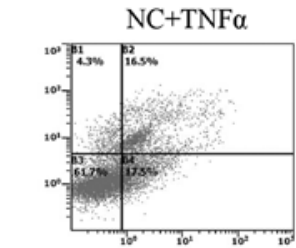

$\mathrm{S} 1+\mathrm{TNF} \alpha$

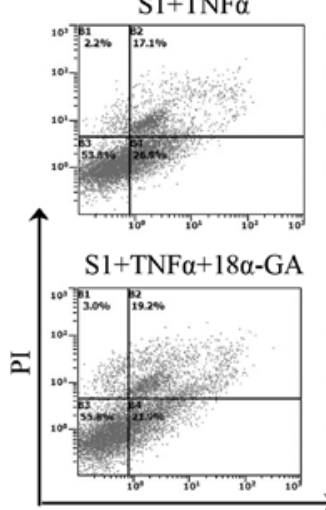

Annexin V
$\mathrm{Dox}+\mathrm{NC}+\mathrm{TNF} \alpha$

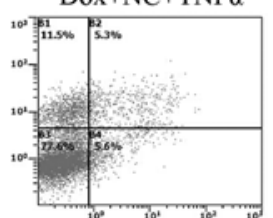

$\mathrm{Dox}+\mathrm{S} 1+\mathrm{TNF} \alpha$



$\mathrm{Dox}+\mathrm{S} 1+\mathrm{TNF} \alpha+18 \alpha-\mathrm{GA}$

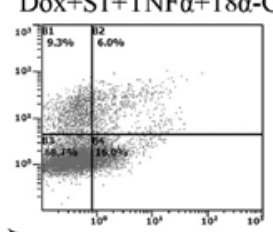



Figure 4. Effect of Cx32 on the apoptosis of HeLa-Cx32 cells after transfection with EGFR siRNA. (A) Using NS siRNA as a negative control (NC), three EGFR siRNAs (S1, S2 and S3) were used to knock down EGFR expression. EGFR siRNA1 (S1) was determined to be the most efficient fragment, and thus was used in further experiments. (B) The results showed that, with or without GJ inhibition by $18 \alpha$-GA, EGFR siRNA did not reverse the anti-apoptotic effect of Cx32 against TNF $\alpha .{ }^{*} \mathrm{P}<0.05 ; \mathrm{n}=3-4 ; \mathrm{n}=1$ represents an independent experiment. S1, EGFR siRNA1.

$(1.25 \mu \mathrm{M})$ was also used in co-treatment with $\mathrm{TNF} \alpha$ to inhibit EGFR. The results showed that, with or without GJ inhibition by $18 \alpha-\mathrm{GA}$, the anti-apoptotic effect of Cx32 against TNF $\alpha+$ afatinib was present (Fig. 3B).

Effect of Cx32 on the apoptosis of HeLa-Cx32 cells after transfection with EGFR siRNA. Due to the multi-functionality of EGFR inhibitors, we used siRNA to specifically reduce EGFR expression in our further experiments. Using an NS siRNA as a negative control, three EGFR siRNAs (S1, S2 and S3) were used to knock down EGFR expression. Among these, EGFR siRNA1 (S1) was determined to be the most efficient fragment, and thus was used in our further experiments (Fig. 4A). The results showed that with or without GJ inhibition by $18 \alpha-\mathrm{GA}$, the anti-apoptotic effect of $\mathrm{Cx} 32$ against $\mathrm{TNF} \alpha$ was present, even after transfection with EGFR siRNA (Fig. 4B).

Cx32 expression correlates with the expression of Cox-2, survivin and $T N F \alpha$ in cervical cancer cells. Cox-2 is an important factor for the prognosis of $\mathrm{CaCx}$. After the upregulation of Cx32 was induced with Dox, we found that Cox-2 was also upregulated (Fig. 5A). Our previous study demonstrated that $\mathrm{Cx} 32$ expression was higher in $\mathrm{CaCx}$ than in normal cervical tissue. Compared with para-carcinoma tissue exhibiting low Cx32 expression, the expression of survivin in $\mathrm{CaCx}$ was markedly increased and coincided with $\mathrm{Cx} 32$ variation (Fig. 5B). Furthermore, in the $\mathrm{CaCx}$ cell line $\mathrm{C}-33 \mathrm{~A}$, after knockdown of Cx32 with siRNA, the expression levels of survivin and $\mathrm{TNF} \alpha$ were found to be reduced (Fig. 5C). As the expression levels of TNF $\alpha$, EGFR and survivin have been associated with anti-apoptotic processes and the tumor micro-environment, these results suggest that $\mathrm{Cx} 32$ may serve as a tumor enhancer in $\mathrm{CaCx}$.

\section{Discussion}

Previous results have indicated that GJs may enhance the bystander effect in tumor cells (15). However, through the upregulation of death receptor 5 and downregulation of $\mathrm{Cx} 43$, carbenoxolone (an inhibitor of GJIC) has been found to enhance 
A

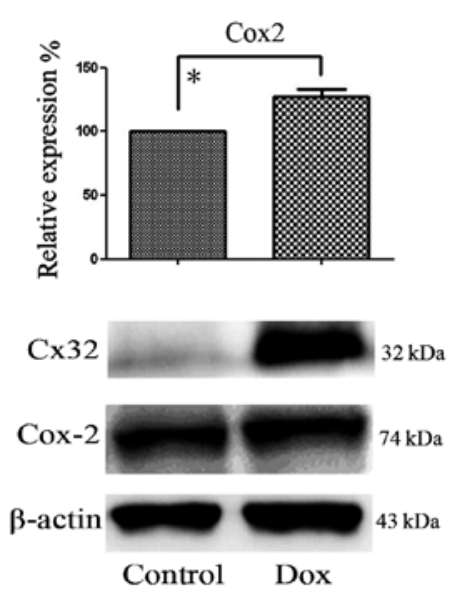

$\mathrm{C}$

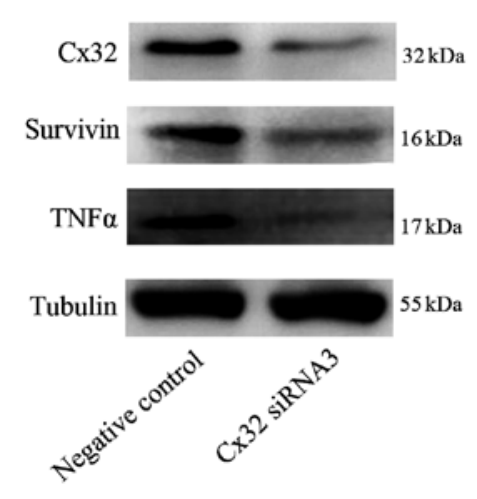

B

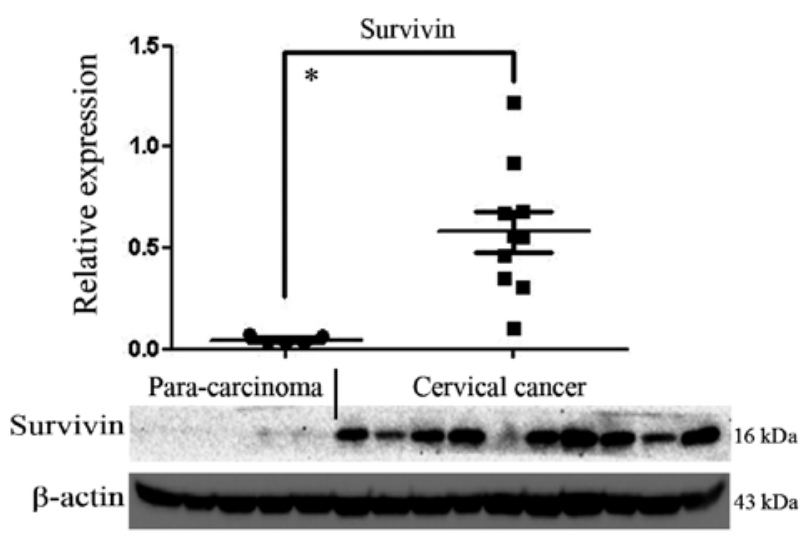

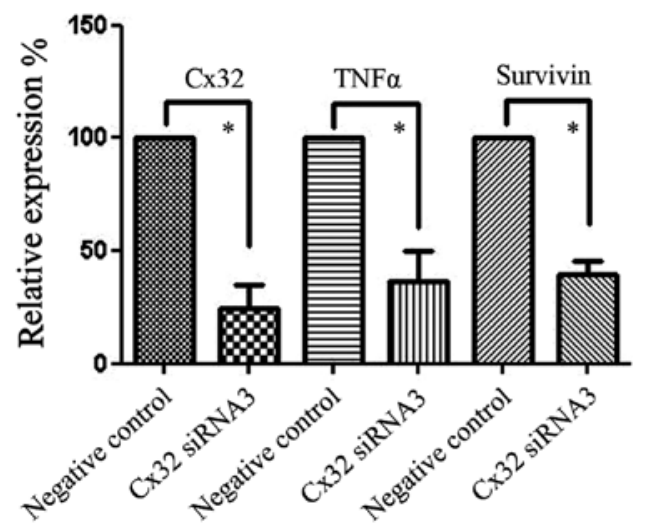

Figure 5. Cx32 expression correlates with the expressions of Cox-2, survivin and TNF $\alpha$ in cervical cancer cells. (A) After the expression of Cx32 was induced with Dox, Cox-2 was also upregulated in HeLa-Cx32 cells $(\mathrm{n}=3)$. (B) Western blot analysis of survivin expression in cervical cancer and para-carcinoma tissues expressing different levels of Cx32 ( $\mathrm{n}=5-10)$. (C) After siRNA knockdown of Cx32 in C-33A cells, the expression levels of survivin and TNFa were reduced $(\mathrm{n}=3) .{ }^{*} \mathrm{P}<0.05 ; \mathrm{n}=1$ represents an independent experiment.

TRAIL-induced apoptosis (16). In contrast to the effects of $\mathrm{Cx} 26$, irradiated HeLa cells expressing $\mathrm{Cx} 32$ have previously showed enhanced survival capacity and greater metabolic activity relative to control cells $(17,18)$. However, whether the promotion of GJIC involving Cx32 can increase or decrease the efficacy of antitumor drugs is not well defined (2). As the effect of GJs on apoptosis is complex, the present study focused on the non-junctional function of $\mathrm{Cx} 32$ in the apoptosis of $\mathrm{CaCx}$ cells.

$\mathrm{Cx}$ proteins may act as signaling effectors and activate the canonical mitochondrial apoptotic pathway, independently of their functional roles within GJs or hemichannels (19). Among the $\mathrm{Cx}$ proteins, $\mathrm{Cx} 43$ is the most widely studied. In a series of breast cancer samples, elevated levels of $\mathrm{Cx} 43$ were found to serve as positive prognostic markers, while elevated levels of Cx30 were shown to be negative prognostic markers (20). Thus, regarding the impacts of $\mathrm{Cx}$ proteins on tumors, $\mathrm{Cx}$ family members and the host tissues should be considered and assessed. Additionally, $\mathrm{Cx}$ mutations and aberrancies in their distribution require evaluation. For instance, aberrant trafficking of a Leu89Pro Cx32 mutant was found to be associated with X-linked dominant Charcot-Marie-Tooth disease (21). Strong Cx43 expression has been detected in the inner mitochondrial membrane within cardiomyocytes (22).
According to our previous study, $\mathrm{Cx} 32$ is also expressed in the nucleus of $\mathrm{CaCx}$ tissue (10), and thus the present study further explored the function of $\mathrm{Cx} 32$ in $\mathrm{CaCx}$ cells.

Through activation of $\mathrm{PKC}-\delta$, EGF can protect $\mathrm{CaCx}$ ME180S cells from apoptosis induced by TNF $\alpha$ (23). EGFR and ErbB2 are important mediators of TNFo-regulated antiapoptotic signals in intestinal epithelial cells (24). To determine whether the anti-apoptotic function of $\mathrm{Cx} 32$ was related to EGFR signaling, we used afatinib and siRNA to inhibit the function and expression of EGFR, respectively. However, the results showed that the effect of $\mathrm{Cx} 32$ on extrinsic apoptosis was not significantly altered after EGFR inhibition. In addition to afatinib, erlotinib can also be used to inhibit EGFR. The process of cell autophagy may serve as a protective mechanism against EGFR inhibitors, as inhibition of autophagy has been found to enhance the sensitivity of erlotinib in EGFR-mutated non-small cell lung cancer (25). Whether the resistive effects of $\mathrm{Cx} 32$ against afatinib and TNF $\alpha$ in the present study are related to autophagy is unclear and warrants further investigation.

A previous study documented that STAT3 inhibition markedly increased the sensitivity of HPV-related cancer to TRAIL-based therapy (26). Notably, it has been reported that EGFR inhibition may be enhanced by inhibition of the STAT3 
pathway; compared with the inhibition of each pathway alone, combined blockade of both the EGFR and STAT3 pathways was more effective against human ovarian cancer in vitro and in vivo (27). Our results showed that in cell groups treated with TNF $\alpha$, p-STAT3 expression was higher in the Cx32 high-expression group, which may explain the resistance of Cx32 to EGFR inhibition. A previous study reported that inhibition of the EGFR oncogene induced formation of an EGFR-TRAF2-RIP1-IKK complex, which stimulated an $\mathrm{NF}-\kappa \mathrm{B}-$ mediated transcriptional survival program (28). In addition, $\mathrm{TNF} \alpha$ regulates $\mathrm{NF}-\kappa \mathrm{B}$ signaling, and thus whether $\mathrm{NF}-\kappa \mathrm{B}$ signaling is a key factor in the resistance of $\mathrm{Cx} 32$ to EGFR inhibition requires further investigation. Additionally, a previous study found that $\mathrm{TNF} \alpha$-induced $\mathrm{NF}-\kappa \mathrm{B}$ activation was not blocked by EGFR or Src inhibition, suggesting that TNFa may exert both EGFR-dependent and -independent effects (29).

Overexpression of survivin is involved in drug resistance in cancer cells, and reduces patient survival rate after chemotherapy and radiotherapy. Antagonism of survivin function renders cancer cells sensitive to the pro-apoptotic affects of $\mathrm{TNF} \alpha$, indicating that survivin blocks the extrinsic pathway of apoptosis (30). Our data showed that survivin expression was reduced in C-33A cells after knockdown of Cx32 with siRNA. This result demonstrates the potential relationship between Cx32 and survivin, which may account for the anti-apoptotic effect of $\mathrm{Cx} 32$ in $\mathrm{CaCx}$ cells.

Several studies have shown that TNF $\alpha$, Fas and TRAIL serve as critical factors in the tumor environment (31). Abnormal secretion of TNF $\alpha$ contributes to a number of human diseases, and has been implicated in tumor development and inflammation (6). Notably, in endotoxemic mice, inhibition of EGFR activation decreased the production of TNF $\alpha$ in the myocardium (32). As our western blot results showed that Cx32 expression was correlated with both EGFR and TNF $\alpha$ expression, it is possible that the relationship between EGFR and TNF $\alpha$ is co-regulated by $\mathrm{Cx} 32$. One speculation is that Cx32 effects the tumor micro-environment by changing the expression of TNF $\alpha$, EGFR, survivin and associated factors, although this requires further investigation.

In conclusion, high expression of $\mathrm{Cx} 32$ appeared to produce anti-apoptotic effects independently of GJs, and also modulated the expression levels of TNF $\alpha, \mathrm{Cox}-2$ and survivin, which may alter the tumor micro-environment in $\mathrm{CaCx}$.

\section{Acknowledgements}

The present study was supported in part by the National Natural Science Foundation of China (grant no. 81473234), the Fundamental Research Funds for the Central Universities (grant nos. 16ykjc01 and 16ykzd11), the Medical Science Foundation of Guangdong Province (grant no. A2015168), and the grant for Development of Science and Technology from the Department of Science and Technology of Guangzhou (grant no. 201704020170).

\section{References}

1. Mao XY, Li QQ, Gao YF, Zhou HH, Liu ZQ and Jin WL: Gap junction as an intercellular glue: Emerging roles in cancer EMT and metastasis. Cancer Lett 381: 133-137, 2016.
2. Aasen T, Mesnil M, Naus CC, Lampe PD and Laird DW: Gap junctions and cancer: Communicating for 50 years. Nat Rev Cancer 16: 775-788, 2016.

3. Mesnil M, Krutovskikh V, Piccoli C, Elfgang C, Traub O, Willecke K and Yamasaki H: Negative growth control of HeLa cells by connexin genes: Connexin species specificity. Cancer Res 55: 629-639, 1995.

4. Zhao B, Zhao W, Wang Y, Xu Y, Xu J, Tang K, Zhang S, Yin $\mathrm{Z}, \mathrm{Wu} \mathrm{Q}$ and Wang $\mathrm{X}$ : Connexin32 regulates hepatoma cell metastasis and proliferation via the p53 and Akt pathways. Oncotarget 6: 10116-10133, 2015.

5. Kawasaki Y, Omori Y, Li Q, Nishikawa Y, Yoshioka T, Yoshida M, Ishikawa K and Enomoto K: Cytoplasmic accumulation of connexin 32 expands cancer stem cell population in human $\mathrm{HuH} 7$ hepatoma cells by enhancing its self-renewal. Int J Cancer 128: 51-62, 2011.

6. Chen Y, Zou Z, Wu Z, Zhao Z, Luo X, Xie C and Liang Y: TNF- $\alpha$-induced programmed cell death in the pathogenesis of acquired aplastic anemia. Expert Rev Hematol 8: 515-526, 2015.

7. Barbisan G, Pérez LO, Contreras A and Golijow CD: TNF- $\alpha$ and IL-10 promoter polymorphisms, HPV infection, and cervical cancer risk. Tumour Biol 33: 1549-1556, 2012.

8. Burtness B, Bauman JE and Galloway T: Novel targets in HPV-negative head and neck cancer: Overcoming resistance to EGFR inhibition. Lancet Oncol 14: e302-e309, 2013.

9. Gaud G, Guillemot D, Jacob Y, Favre M and Vuillier F: EVER2 protein binds TRADD to promote TNF- $\alpha$-induced apoptosis. Cell Death Dis 4: e499, 2013.

10. Zhao Y, Lai Y, Ge H, Guo Y, Feng X, Song J, Wang Q, Fan L, Peng Y, Cao M, et al: Non-junctional Cx32 mediates anti-apoptotic and pro-tumor effects via epidermal growth factor receptor in human cervical cancer cells. Cell Death Dis 8: e2773, 2017.

11. Zheng RR, Huang M, Jin C, Wang HC, Yu JT, Zeng LC, Zheng FY and Lin F: Cervical cancer systemic inflammation score: A novel predictor of prognosis. Oncotarget 7: 15230-15242, 2016.

12. Koreen IV, Elsayed WA, Liu YJ and Harris AL: Tetracyclineregulated expression enables purification and functional analysis of recombinant connexin channels from mammalian cells. Biochem J 383: 111-119, 2004.

13. Goldberg GS, Bechberger JF and Naus CC: A pre-loading method of evaluating gap junctional communication by fluorescent dye transfer. Biotechniques 18: 490-497, 1995.

14. Qi Z, Shen L, Zhou H, Jiang Y, Lan L, Luo L and Yin Z: Phosphorylation of heat shock protein 27 antagonizes TNF- $\alpha$ induced HeLa cell apoptosis via regulating TAK1 ubiquitination and activation of p38 and ERK signaling. Cell Signal 26: 1616-1625, 2014.

15. Zhang Y, Tao L, Fan L, Peng Y, Yang K, Zhao Y, Song Q and Wang Q: Different gap junction-propagated effects on cisplatin transfer result in opposite responses to cisplatin in normal cells versus tumor cells. Sci Rep 5: 12563, 2015.

16. Yulyana Y, Endaya BB, Ng WH, Guo CM, Hui KM, Lam PY and Ho IA: Carbenoxolone enhances TRAIL-induced apoptosis through the upregulation of death receptor 5 and inhibition of gap junction intercellular communication in human glioma. Stem Cells Dev 22: 1870-1882, 2013.

17. Autsavapromporn N, De Toledo SM, Jay-Gerin JP, Harris AL and Azzam EI: Human cell responses to ionizing radiation are differentially affected by the expressed connexins. J Radiat Res (Tokyo) 54: 251-259, 2013.

18. Zhao Y, de Toledo SM, Hu G, Hei TK and Azzam EI: Connexins and cyclooxygenase- 2 crosstalk in the expression of radiationinduced bystander effects. Br J Cancer 111: 125-131, 2014.

19. Carette D, Gilleron J, Chevallier D, Segretain D and Pointis G: Connexin a check-point component of cell apoptosis in normal and physiopathological conditions. Biochimie 101: 1-9, 2014.

20. Teleki I, Szasz AM, Maros ME, Gyorffy B, Kulka J, Meggyeshazi N, Kiszner G, Balla P, Samu A and Krenacs T: Correlations of differentially expressed gap junction connexins Cx26, Cx30, Cx32, Cx43 and Cx46 with breast cancer progression and prognosis. PLoS One 9: e112541, 2014.

21. Da Y, Wang W, Liu Z, Chen H, Di L, Previch L and Chen Z: Aberrant trafficking of a Leu89Pro connexin32 mutant associated with X-linked dominant Charcot-Marie-Tooth disease. Neurol Res 38: 897-902, 2016.

22. Miro-Casas E, Ruiz-Meana M, Agullo E, Stahlhofen S, Rodríguez-Sinovas A, Cabestrero A, Jorge I, Torre I, Vazquez J, Boengler K, et al: Connexin43 in cardiomyocyte mitochondria contributes to mitochondrial potassium uptake. Cardiovasc Res 83: 747-756, 2009. 
23. Akca H, Akan SY, Yanikoglu A and Ozes ON: Suppression of TNF-alpha mediated apoptosis by EGF in TNF-alpha sensitive human cervical carcinoma cell line. Growth Factors 21: 31-39, 2003.

24. Yamaoka T, Yan F, Cao H, Hobbs SS, Dise RS, Tong W and Polk DB: Transactivation of EGF receptor and ErbB2 protects intestinal epithelial cells from TNF-induced apoptosis. Proc Nat Acad Sci USA 105: 11772-11777, 2008.

25. Li YY, Lam SK, Mak JC, Zheng CY and Ho JC: Erlotinibinduced autophagy in epidermal growth factor receptor mutated non-small cell lung cancer. Lung Cancer 81: 354-361, 2013.

26. Nakamura H, Taguchi A, Kawana K, Kawata A, Yoshida M, Fujimoto A, Ogishima J, Sato M, Inoue T, Nishida $\mathrm{H}$, et al: STAT3 activity regulates sensitivity to tumor necrosis factorrelated apoptosis-inducing ligand-induced apoptosis in cervical cancer cells. Int J Oncol 49: 2155-2162, 2016.

27. Wen W, Wu J, Liu L, Tian Y, Buettner R, Hsieh MY, Horne D, Dellinger TH, Han ES, Jove R, et al: Synergistic anti-tumor effect of combined inhibition of EGFR and JAK/STAT3 pathways in human ovarian cancer. Mol Cancer 14: 100, 2015.
28. Blakely CM, Pazarentzos E, Olivas V, Asthana S, Yan JJ, Tan I, Hrustanovic G, Chan E, Lin L, Neel DS, et al: NF- $\kappa$ B-activating complex engaged in response to EGFR oncogene inhibition drives tumor cell survival and residual disease in lung cancer. Cell Rep 11: 98-110, 2015.

29. Kakiashvili E, Dan Q, Vandermeer M, Zhang Y, Waheed F, Pham M and Szászi K: The epidermal growth factor receptor mediates tumor necrosis factor-alpha-induced activation of the ERK/GEF-H1/RhoA pathway in tubular epithelium. J Biol Chem 286: 9268-9279, 2011.

30. Cheung CH, Sun X, Kanwar JR, Bai JZ, Cheng L and Krissansen GW: A cell-permeable dominant-negative survivin protein induces apoptosis and sensitizes prostate cancer cells to TNF- $\alpha$ therapy. Cancer Cell Int 10: 36, 2010

31. Cullen SP and Martin SJ: Fas and TRAIL 'death receptors' as initiators of inflammation: Implications for cancer. Semin Cell Dev Biol 39: 26-34, 2015.

32. Sun X, Liang J, Yao X, Lu C, Zhong T, Hong X, Wang X, Xu W, $\mathrm{Gu} \mathrm{M}$ and Tang J: The activation of EGFR promotes myocardial tumor necrosis factor- $\alpha$ production and cardiac failure in endotoxemia. Oncotarget 6: 35478-35495, 2015. 